\title{
A FORMA DIFÍCIL OU DA ARTEPENSAMENTO EM AMADEO, DE MÁRIO CLÁUDIO
}

\author{
THE DIFFICULT FORM OR ON ARTTHOUGHT IN AMADEO, BY MARIO CLÁUDIO
}

Lucia Melo SOUSA

Universidade Estácio de Sá

luciams27@gmail.com

\begin{abstract}
Resumo: A obra do escritor português Mário Cláudio se destaca por estabelecer o diálogo entre a literatura e as outras artes. O romance Amadeo, que faz parte da Trilogia da Mão, juntamente com dois outros romances intitulados Guilhermina e Rosa, ficcionaliza a vida do pintor modernista, e também português, Amadeo de Souza-Cardoso. A relação entre a palavra e a imagem já se insinua no título, bem como nas reproduções de fotos pessoais e telas do artista dentro do livro. O diálogo, porém, entre a palavra e a imagem, vem de longa data: de Simónides de Keos, passando por Horácio da famosa sentença "Ut pictura poesis", pelo Paragone de Da Vinci e o Laocoonte de Lessing, a questão se impôs. Trago a discussão para a contemporaneidade a partir do conceito de espaço biográfico, ou seja, uma forma biográfica desenvolvida no romance de Mário Cláudio, a fim de mostrar que este espaço, por se revelar tensivo, é capaz de problematizar as fronteiras dos gêneros tradicionais, como a biografia e o romance, e promover a emergência de uma forma híbrida e expansiva, em que as atividades crítica e criativa se fundem e confundem, e 0 pensar e o fazer dão ensejo à configuração de uma artepensamento.
\end{abstract}

Palavras-Chave: Literatura Portuguesa-Mário Cláudio-Amadeo de SouzaCardoso-Pintura-Neobarroco

\begin{abstract}
The works of the writer Mário Cláudio stands out because it establishes a dialogue between literature and other arts. The novel Amadeo, which is part of the trilogy Trilogia da Mão, alongside with two other novels named Guilhermina and Rosa, fictionalizes the life of the Portuguese modernist painter Amadeo de Souza-Cardoso. The relationship between word and image is already insinuated in the title, as well as in the reproductions of personal pictures and canvases of the artist inside the book. The dialogue between work and image, however, comes from a long time ago: this question is presented from Simónides of Keos, passing through Horácio of the famous sentence "Ut picture poesis", through Da Vinci's Paragone and Lessing's Laocoonte. I bring the discussion to contemporaneity from the concept of geographical space, which is a biographical way developed in Mário Cláudio's novel in order to show that this space, because it is revealed to be a tensile one, is capable of problematizing traditional genre boarders like the biography and the novel, and of promoting the emergency of a hybrid and expansive form, in which critic and creative activity merge and mix, and the act of thinking and doing give space to the shaping of an art-thought.
\end{abstract}


Keywords: Portuguese Literature, Mário Claudio, Amadeo de Sousa-Cardoso, Painting, New Baroque style.

Je me suis juré de mourir en peignant

Paul Cézanne ${ }^{1}$

O que chamo de "Grande Arte" é simplesmente a arte que exige que todas as faculdades de um homem sejam utilizadas nela, e cujas obras sejam tais que todas as faculdades de outro sejam invocadas e se interessem por entendê-las

Paul Valéry²

Alguns chegam a pensar que a meditação sobre a Arte, o rigor do raciocínio aplicado à cultura, só podem pôr a perder um poeta, uma vez que o principal e mais encantador objeto do seu desejo deve ser o de comunicar a impressão de um estado nascente (felizmente nascente) de emoção criadora que, pela virtude da surpresa e do prazer, possa indefinidamente livrar o poema de qualquer reflexão crítica.

Paul Valéry ${ }^{3}$

O diálogo do romance de Mário Cláudio com outras manifestações artísticas começa pelo título do livro: Amadeo. Nesse romance, a forma artística privilegiada será a pintura de Amadeo de Sousa-Cardoso que, junto com Almada-Negreiros, desponta com um dos maiores nomes da arte modernista em terras lusas. É, então, sobre a vida do pintor de Amarante que o texto de Mário Cláudio fala, ou, melhor dizendo, pinta com palavras a vida (de) escrita do artista. A relação estabelecida com a obra de Amadeo, como se disse, se indicia já pelo título e pela reprodução do quadro "Procissão do Corpus Christi, Em Amarante", datado de 1913. Esta reprodução se encontra na edição da Imprensa Nacional Casa da Moeda, de Lisboa. Na edição das Publicações Dom Quixote, há a reprodução da tela "A Mão da Artista”, de Aurélia de Sousa. Mário Cláudio, nesta

\footnotetext{
${ }^{1}$ RILKE, Rainer Maria. Cartas sobre Cézanne. Rio de Janeiro: 7Letras, 2006. p.82.

2 VALÉRY, Paul. Degas Dança Desenho. São Paulo: Cosac\&Naify, 2003. p.149.

${ }^{3}$ VALÉRY, Paul apud NOVAES, Adauto. In: Artepensamento. São Paulo: Companhia das Letras, 2006. p.11.
} 
última edição, intitulada de Trilogia da Mão, não só dialoga com a pintura de Amadeo de Sousa-Cardoso, mas também com outras linguagens artísticas, como a música de Guilhermina Suggia e a cerâmica de Rosa Ramalha. A imagem da mão aí aparece para metonimizar o trabalho do artista e, em particular, de três artistas portugueses que se empenham no "emprego das mãos na matéria transformável." (CLÁUDIO, 1993, p.117)

É preciso dizer que o diálogo empreendido por Mário Cláudio - e outros escritores - com outras linguagens artísticas vem de longa data. O nome de Simónides de Keos figura ao lado do de Horácio da Arte Poética como aqueles que iniciam e indiciam a relação entre a poesia e a pintura na Antiguidade, passando por Leonardo da Vinci em sua polêmica Teoria do Paragone século $\mathrm{XVI}$, bem como o de Lessing, já no século XVIII, com o seu estudo sobre o Laocoonte. Horácio, com a sentença "Ut pictura poesis," advoga a favor da poesia ao dizer que a pintura é como a poesia, uma vez que o modo de imitar, realizado pela pintura, estava submetido às leis da Poética e da Retórica, ou seja, a imitação pela pintura estava presa aos ditames do Logos e subjugada à pedagogia do pensamento racional.

A supremacia da palavra sobre a imagem vigorou até o século $\mathrm{XVI}$, quando surgiu a polêmica levantada por Da Vinci, a partir de sua questão do Paragone. Nela Da Vinci vai defender a superioridade da pintura sobre a poesia, ao dizer que, ao contrário da poesia, "à pintura caberia a possibilidade de pôr as coisas como que realmente diante dos olhos, como se fossem naturais, como se fosse a própria Natureza" (SELIGMANN-SILVA, 1998, p. 9). Segundo Da Vinci, a pintura traria de forma imediata, ou seja, sem mediação, as coisas para diante dos olhos das pessoas. A discussão segue até o Laocoonte, de Lessing, quando ele, a partir de seu estudo, vem requerer que as comparações entre as diferentes formas de arte se estabeleçam levando em conta os diferentes meios de imitação. Com isso, levanta a reflexão sobre os peculiares meios de imitação de cada arte e, portanto, sobre as fronteiras entre elas, ao defender que sejam avaliadas pelos seus próprios meios e contextos de recepção. A partir de então, a antiga sentença horaciana entra em crise, e o diálogo entre a poesia e a 
pintura, entre a imagem e a palavra, se dará em outras bases, fazendo com que seja superada a clássica concepção mimética das artes.

O espaço biográfico em Amadeo se apresenta como a arte do pintor: móvel e movente. Um dos trabalhos do nortenho, em guache, de 1915, intitula-se "Expositions Mouvantes. Corporation Nouvelle". Neste espaço se tensionam vários limites, bem como se travam várias discussões, a começar pelo questionamento e esgarçadura de fronteiras entre os gêneros discursivos e pelo desdobrar deste mesmo espaço em outros meios expressivos. Chamo de espaço biográfico o que Rodrigo Naves (2011) chamaria de forma difícil, ao definir boa parte da produção da arte brasileira, isto é, uma forma problemática e problematizada, tensa, porque paradoxal, que se configuraria como um espaço em "suspensão", que sugeriria menos de uma solução artística e mais de um processo de gênese das formas. Na interpretação de Naves, na fragilidade da forma estaria inscrita, pelo contexto social e econômico da emergência da arte brasileira, a sua forma de resistência. Penso ser produtivo aproximar o conceito de Forma Difícil de Naves ao de Espaço Biográfico, ou seja, da Forma Biográfica presente nos romances e novelas de Mário Cláudio como um espaço em que limiar e limite de meios expressivos se problematizam e tensionam, a fim de perspectivarem, pelo uso e experimentação de outras linguagens artísticas, outras formas de pensar e estruturar o discurso literário.

No caso do romance, o meio expressivo apropriado pelo escritor será a linguagem pictórica de Souza-Cardoso, pois Mário Cláudio, ao se apoderar dela, apresenta um texto que vai se constituir à imagem e semelhança da obra cubista do artista de Amarante.

As palavras de Mário Cláudio, assim como as tintas de Amadeo, se compõem e decompõem e se apegam aos rigorosos dedos do escritor. Olhos e dedos atenciosos na busca da melhor palavra para dar a ver, não o quadro pintado com tinta, mas o pintado com palavras, que se compõem e decompõem não de acasos, mas da necessidade de mapear a "geografia vital" da pintura de Amadeo, mediante o discurso literário. Não seria demais relembrar o que disse Cerdeira (2000): em Amadeo não é só a tela que se deseja texto, mas o texto que se deseja e se revela tela. E nesse desejo se corporifica o elogio ao metódico 
movimento da mão de um pintor, que se constrói à maneira de um geômetra sempre a buscar a justa medida, ainda que de modo tenso, como se mostrou, de seu ofício. Essa medida justa se revela em pequenos mas significativos adjetivos, que dão a ver e a conhecer o modo de ser, porque de pintar, de SouzaCardoso: "Na desordem da Cité Falguière irritava quem dele se aproximasse, meticuloso até o grotesco, organizando-se até a doença. Viam-no enfileirando os trabalhos, espanejando os coxins, esticando a fímbria do tapete" (CLÁUDIO, 1993 p.48. Grifos nossos). Ou ainda: "Fatigado da encenação, acomodava-se no atelier ordenadíssimo, sentava-se na chaise-longue vestindo sempre a capa-de-honras, passando em revista os esboços do álbum, cônscio de uma qualidade superior" (id, ibid, p.53. Grifos nossos).

Em "monomania da poupança" e de "pincéis cuidadosamente perfilados" (id, ibid, p.52. Grifos nossos), de uma disciplina que beira "até a doença", erigia Amadeo a sua Casa de Pintura. Programada, arquitetada, organizada "até a doença”, bem como de palavras, "cuidadosamente perfiladas", se ergue a Casa textual de Mário Cláudio:

\begin{abstract}
Metodicamente labutava, sem paixão nem pressa, com a exasperação tão-só de quem não reconhece na pujança do próprio corpo efeméride a festejar. Configurava a acção como intérmino teorema, progressão de pedra sobre pedra, vendo-se em tal da fibra dos grandes construtores. Nada desses prodígios de acaso, dessa entrega a ninfas e harpias que caracteriza a lenda dos malvados. O seu era o ofício dos misantropos que disso se não lastimam, dos que no deserto descortinam a legítima circunstância de seu respirar.

(CLÁUDIO, 1993, p.57. Grifos nossos)
\end{abstract}

Não sem razão nos diz Eduardo Prado Coelho em arguta observação:

\begin{abstract}
Porque a Casa insinua-se: e este livro, Amadeo, no torvelinho das suas peças, e jogo das suas manchas tipográficas e dos seus espaços em branco, é a exibição desenvolta dessa sabedoria da pedra e do papel, dos alicerces cravados na terra e dos corredores abertos ao vento. $\mathrm{O}$ arquiteto pensa, imagina, traça, modela, antes de realizar. E, no dizer de Mário Cláudio projectado em Amadeo, todo o artista é um arquiteto. Há mesmo neste livro uma subtil desvalorização daquelesque demasiadamente se inclinam para o lado do mero tumulto inspirador sem atentarem na finíssima rede de barreiras, mediações e vigilância que toda a criação se sustenta. (COELHO, 1988, p.79)
\end{abstract}

Talvez Mário Cláudio vislumbre, como Almada em 1917, e colha do estilo do pintor, a mesma "vitalidade", o mesmo impulso para o novo, para a exploração 
inventiva da arte, desta que, movida pelo cata-vento Amadeo, o incita a se inovar em busca de outras linhas e outros espaços. O escritor busca no pintor o objeto de sua especulação - nos dois sentidos do termo- e o semelhante pensamento que preexiste à ação. Concebe o conceito de arte com os mesmos olhos: como renovação, mas no ato, na ação que se faz pensamento. Busca no similar movimento em direção ao novo a dificuldade própria do grande artista "que nunca se sentará sobre a própria obra” (id, ibid, p.51. Grifo nosso). É na propositada, porque pensada, dificuldade presente na estrutura do romance, fragmentada e labiríntica - porque, no nível sintático tal dificuldade não se mostra tão acentuada - que o romance do portuense também vai ao encontro do conceito de arte neobarroca, como assim a define o italiano Omar Calabrese (1987). Por isso, uma de suas marcas é a estrutura de jogo em que, pela consciência do artifício, o autor cria toda uma sorte de lacunas, fragmentos, que apresentam uma certa dificuldade, a fim de acionar a atenção do leitor para que ele, pelo esforço de entendimento e interpretação, também venha a participar do jogo da criação. Denominar-se-iam produtos como o romance de Mário Cláudio de obras abertas, inacabadas, porque incitariam o recomeçar da manipulação das peças do jogo, na intenção de multiplicar outros sentidos e leituras e interpretações. Lembremos que esse tipo de dificuldade também era caro à estética da cultura barroca, como assinala Antonio Maravall (1997).

A escrita de Papi/ Mário Cláudio no romance da biografia de Amadeo, assim como o estilo e as telas do português descritas, recriadas pela pena/pincel, também constitui-se de planos justapostos e tensivos: "A Casa de Manhufe alberga quem larga para as estradas do Planeta, nela se surpreende, em certos veios da madeira, no ofegar da humidade sob o granito dos degraus, "esta rede de destinos que se encontram, se cumprem, desaparecem" (id, ibid, p.22. Grifos nossos). Uma "rede de destinos" que se articula e se cruza no jogo especular e labiríntico em que se converte o gênero biográfico nas mãos do hábil escritor, e que também se materializa na dupla dimensão das Casas em que estão tensionados o espaço da criação e o da crítica.

Mário Cláudio desnuda a estrutura de seu texto para, assim, desmitificar o ato criador como um ato de inspiração ou só, como pensa Valéry, como um 
simples acaso movido por uma emoção estética. Mostra que, atrás da tela e do texto, só encontraremos "os instrumentos" próprios de que cada meio expressivo se serve para construir suas realidades no mundo da arte: ou seja, no caso da pintura a cor, a luz, as formas e as linhas, no da literatura, as palavras. Não é sem razão que o escritor se desdobra no personagem Papi que, por sua vez, se desdobra em Frederico, o qual se desdobra em Álvaro, e todos se desdobram em Amadeo, numa narrativa que goza de se dobrar sobre si mesma, como se quisesse gritar: sou isto! Dobra sobre dobra, representação da representação.

Lembremos, mais uma vez, do quadro As Meninas, de Velásquez. O procedimento de se pintar pintando configura-se semelhante ao procedimento utilizado por Mário Cláudio em Amadeo: o de um escritor que trabalha sobre a escrita de uma biografia, e, nesse movimento, enceta uma dupla condição: a de fazer o objeto Amadeo, com seu cata-vento colorido, o seu movimento à ação criadora, mas também e, sobretudo, como um movimento de crítica, de autocrítica, questionamento e dúvida acerca do próprio processo criativo: "Pressente-Ihe nas cartas um pensamento que preexiste à acção, o que é muito raro nos artistas" (id, ibid, p.52).

Ao se interrogar enquanto interroga o objeto Amadeo, que "interrogava 0 próprio nome" (id, ibid, p14) - nome que, como a obra, só podia ser construído como uma dúvida - Mário Cláudio levanta o questionamento acerca do estatuto e do valor da arte e do artista em tempos de tão relativos valores, como os da chamada pós-modernidade ou idade neobarroca. O valor do artista e da obra parece não estar no objeto artístico acabado, terminado, mas sim no processo, no labor e no tempo dispensados na pesquisa da matéria-prima para a fabricação dos temas. Temas que já aparecem na disposição do olhar, no ato perceptivo. Reflete Ponty: "Só se vê o que se olha" (PONTY, 2004, p.16). Por isso, a Casa de Manhufe é a imagem a atravessar todo o texto, no movimento do cata-vento que a habita, pois ela já existia antes de ser, de fato, pintada, porque já se revelava antes na pesquisa da terra, das cores e da luz, bem como "dos dedos" da criança que interrogava o próprio nome e interrogava a própria obra. Perceber e pensar se tensionam e fazem parte da mesma moeda. Percepção e pensamento se coadunam e se hibridizam num mesmo espaço: o 
da criação. Lemos no diário do sobrinho de Papi: "É no entanto de Amadeo de Souza-Cardoso que se ocupa este livro, de sua obra e da evolução que vai sofrendo, de como lida com riscos e massas até chegar aonde por momentos se julga ter chegado, lugar todavia a que nunca chega" (id,ibid, p.73). Para o projeto de "certeza conjectural", pois em processo da criação da obra, metaforizado no "minitural catavento" (id, ibid, p.107), haverá um "norte irrealizável". Porque, se realizado, seria como se defrontar, "face-a-face", com "monstro sem contorno, mas de hálito álgido e fétido, a que ninguém sonha jamais atribuir um nome" (id, ibid, p.280). Por isso: "Amadeo, na incessante vertigem da produção, apenas se teria por predestinado enquanto libérrima criatura, cara-a-cara com o destino" (id, ibid, p.112). A vertigem, o movimento incessante da produção/catavento, configurava-se na tentativa de não se defrontar com a própria obra, senão seria o encontro face a face com a própria morte. Pintar consiste em viver a se doar à vida da criação, da arte, representando, assim, uma maneira de ficar, permanecer mediante a ação e o labor do "intérmino teorema" (id, ibid, p.57). Diz-nos o biógrafo:

\footnotetext{
Na pintura, também, será a mesma a natureza. Digere quanto vê, rabisca ao canto do calendário ilações e memoranda, predispõe à aprendizagem sem mestres ungidos, vertiginosa ginástica de se ser e de se perder. Não são assim os inspirados, arrebatados por uma águia que nem os arrasa nem os salva. Assim são, porém, os desbravadores de continetes, alguns atletas sem ideologia política, muitos dos artesãos que gravaram siglas na cantaria das catedrais. Ele não perpassa, fica. (CLÁUDIO, 1993, p.52. Grifos nossos)
}

Fica porque, como diz Klee (2001), o artista "confere duração à gênese". E ela consiste no movimento da busca de ser artista, pois ser artista é "ser". No processo do "intérmino teorema" investe-se toda a energia na operacionalização da obra, daquilo que Valéry definiu assim: "o poeta dedica-se a definir e a comunicar uma linguagem na linguagem" (VALÉRY apud NOVAES, 1994, p.11). Daí o tempo, a dedicação e a atenção aos materiais para a fabricação das matérias-primas-temas pictóricos: "descendo ao Porto, ao "Araújo \& Sobrinho", a adquirir o papel Nationale e a laca de rosa que só lá dizia achar" (id, ibid, p.88. Grifos nossos). Ou, ainda: "Era sinistro o Inverno, apenas redimido pelo folgar de conhecimentos sobre o mistério dos óleos" (id, ibid, p.89. Grifos 
nossos). No deslocamento do olhar e no "emprego da mão na matéria transformável" ou no cultivo da necessidade de indagar "da vocação dos materiais que Ihes passavam pelas mãos." (id, ibid, p.17) consistia a forma de ficar ou de ficar na forma.

No antes, "no pensamento que preexiste à ação", na terra e em Manhufe enraizados em seus dedos, mãos e olhos, na "laca de rosa" que só encontraria no "Araújo e Sobrinho" ou no "conhecimento do mistério dos óleos", perdurariam as linhas, cores e luz da pintura, porque da vida, de Souza-Cardoso.

Mas nenhum jogo de dados abole o acaso, pois dentro da Casa pictórica e textual, muito bem traçada e arquitetada, "em cujo interior uma lamparina eterna sustentava uma chama azul e amarela, minuscularmente pulsando" (id, ibid, p.14. Grifos nossos), também se plantava um menino e seu vira-vento a turvar a mais metódica perspectiva. Entre a linha vertical clássica e a diagonal barroca, entre a razão e a sensibilidade, entre a luz e a sombra, a contenção e a dispersão, ou entre artepensamento, se ergue Amadeo.

O romance Amadeo desnuda o processo da escrita de um diário, o qual nos desvela a escrita de uma biografia, que, por sua vez, se manifesta e se insinua autobiográfica: "Hoje abeiro-me da 'banca' do tio, decifro-lhe as notas" (id, ibid, p.49-50). O texto de Mário Cláudio sugere a "teia do biógrafo biografado que se autobiografa" (MORÃO, 1993, p.155). Reflete Benedito Nunes: "Pensar o tempo significa, portanto, a obrigação de pensar na linguagem que o diz e que 'nele' se diz" (NUNES, 1997, p.75). Talvez seja por isso que Papi, em seu movimento de capturar o cata-vento Amadeo, ao se deslocar até Paris e lá deambular pelas ruas e pelos lugares em que viveram Amadeo e os de sua geração, na primeira década do século XX, encontra só os vestígios: de lugares, de memórias, do tempo de uma vida que já passara, impossível de ser recuperada em seu todo, mas tão-só possível via a intuição e a imaginação criadora do biógrafo. Constata Papi em carta de Paris: 'Os noctívagos' são os inimigos número um da biografia. Inventam um tempo e julgam-se lá" (id, ibid, p.78).

Papi, na Paris dos anos 80, só encontra as ruínas do tempo e do espaço de Amadeo de Souza-Cardoso, bem como as próprias de Paris dos anos 80 do 
século $X X$, a do seu tempo, pois esta se descaracteriza frente ao frenético movimento da cultura americana globalizada presente nos "american-bares" (id, ibid, p.75). Dos anos brilhantes, rebeldes e utópicos, dos tempos em que Paris era uma festa: "Vêem-se restos de cenário de arrabalde, um único atelier sobejante, casas supinamente familiares, Citroëns estacionados" (id, ibid, p.75. Grifos nossos), e na Cité Falguière: "Em lugar do velho catorze, com seus patins e barracões, existe agora um prédio banal de sete andares" (id, ibid, p.75). Percebe-se, no flanar de Papi por Paris, que a cidade brilhante e cheia de entusiasmo que recebeu Amadeo e os de sua geração no presente se encontra desfigurada e degradada pela ação de uma globalização cultural que tudo unifica e banaliza. Do passado e da história dos idos e brilhantes anos 10 e 20 pouco se preservou. Papi se decepciona por não encontrar a Cité Falguière de Amadeo, Modigliani, Braque, Hemingway e tantos outros que por lá circularam nos anos rebeldes e brilhantes da Cidade Luz. E, por constatar que o passado de Amadeo - como o próprio biografado - se revela indômito, só lhe resta transformar o pintor em personagem de um romance que ele configura num cromático e prismático jogo, ao estilo cubo-futurista do amarantino, em torno do qual, à época de sua morte, girava o seu cata-vento colorido de personagens, memórias, espaços e tempos. Caberia ainda dizermos que, no jogo de encaixe das narrativas, estaria embutido o jogo de espelhos, prismático, que revelaria a superfície de linguagem ou linguagens no qual se montam o tabuleiro, o "puzzle", e as peças no jogo da criação artística. Desvelar-se-ia, assim, que este jogo, no caso da literatura de cunho neobarroco, como se apresenta a de Mário Cláudio, se joga mediante os processos da citação, da referencialização e autorreferencialização, da fragmentação, da assunção consciente de uma estrutura labiríntica, por isso mesmo elíptica, dos textos. Ou seja: de palavra, de literatura. Diz Frederico ao espiar o trabalho do tio:

Que diria Papi se soubesse da astúcia com que Ihe espreito a escrita, intenso e o torturado como um voyeur? E que significa este livro outro que vou preenchendo, de fragmentos ligados por um discurso absurdo? E que pensaria Amadeo, não já de que de si um tio magica sob a vigilância de um sobrinho, mas desta outra vida, quem sabe se mais autêntica, acumulada na fantasia do último? (CLÁUDIO, 1993, p.91-2) 
Ou, ainda, o jogo mediante o processo da palavra, que se renova e se movimenta ao colher na lição da pintura novas linhas textuais. No jogo metamorfótico e anamorfótico da linguagem (linguagens), se revelaria, então, sua própria superfície, como escreve Barthes ao comentar um texto neobarroco de Sarduy: "que não há nada para ver por detrás da linguagem, e que a palavra, longe de ser o atributo final e o último retoque da estátua humana, como diz o mito enganador de Pigmaleão, nunca é senão a sua extensão irredutível" (BARTHES, 1984, p.210). Atentemos para o que diz Álvaro, o amigo de Frederico, em carta ao personagem Mário Cláudio:

\begin{abstract}
São os quatro cadernos de capa de oleado em que Papi, e não vejo razão para desvendar agora um nome que por certo não terá dificuldade em determinar, verteu em sua letra microscópica, quase diria científica, a sinopse daquilo que julgo projectaria como Vida de Amadeo de SouzaCardoso. É ainda, o que mais me doeu alienar, o pequeno maço de folhas em que Frederico, meu amigo, foi dando conta de si e do trabalho a que seu Tio se dedicava. (CLÁUDIO, 1993, p.115)
\end{abstract}

Percebe-se que as perspectivas elípticas, porque tortuosas e labirínticas, do texto, o qual se constrói do entrecruzamento das vozes narrantes, vão não só questionando, mas também, e sobretudo, desautorizando as vozes absolutas de eventuais autores, bem como descentralizando os seus respectivos lugares fixos e possíveis verdades acerca do biografado como, igualmente, do biógrafo, daquele que tem o seu nome ao lado do nome do artista na capa do livro intitulado Amadeo. Parafraseando o poeta francês Paul Verlaine: tudo configurar-se-á especulação, logo, literatura.

\title{
Referências bibliográficas
}

BARTHES, R. A Câmara Clara. Tradução Júlio Castanõn Guimarães. Rio de Janeiro: Nova Fronteira, 1984.

CALABRESE, O. Idade Neobarroca. Tradução: Carmen de Carvalho e Artur Morão. Lisboa: Edições 70, 1987.

CERDEIRA, T. C. "Um pintor e dois olhares: Amadeo entre Almada e Mário Cláudio." In: $O$ avesso do bordado; ensaios de literatura. Lisboa: Caminho, 2000. 
COELHO, E. P. Amadeo. In: A noite do mundo. Lisboa: Imprensa Nacional/Casa da Moeda. Lisboa: 1988.

CLÁUDIO, M. Amadeo. Lisboa: Dom Quixote, 1993.

KLEE, P. Sobre a arte moderna e outros ensaios. Tradução: Pedro Süssekind. Rio de Janeiro: Jorge Zahar Editor, 2001.

MARAVALL, A. A Cultura do Barroco. Tradução: Silvana Garcia. São Paulo: Edusp, 1997.

MORÃO, P. Mário Cláudio. In: Viagens na terra da palavra. Lisboa: Edições Cosmos, 1993.

NAVES, R. A forma difícil: ensaios sobre a arte brasileira. São Paulo: Companhia das Letras, 2011.

NOVAES, A. Artepensamento. São Paulo: Companhia das Letras, 2006.

NUNES, B. Introdução à Filosofia da Arte. São Paulo: Ática, 2000.

RILKE, R. M. Cartas sobre Cézanne. Tradução: Pedro Süssekind. Rio de Janeiro: 7 Letras, 2006.

SELIGMANN-SILVA, M. Introdução/Intradução: Mímesis, Tradução, Enárgeia e a Tradição da ut pictura poesis. In: LESSING, G.E. Laocoonte ou sobre as fronteiras da Pintura e da Poesia. São Paulo: Iluminuras, 1998.

VALÉRY, P. Degas Dança Desenho. Tradução: Christina Murachco e Célia Euvaldo. São Paulo: Cosac \& Naify, 2003. 